\title{
A Conceptual Framework for Describing the Role of Employer Branding, Person-Organization Fit and Employee Engagement in Shaping Organizational Citizenship Behavior
}

\author{
Alaa Ibrahim Lary \\ Azman Hashim International Business School, Universiti Teknologi Malaysia; College of \\ Business Administration, University of Business and Technology Jeddah, Saudi Arabia. \\ E-mail: a.lary@ubt.edu.sa; alaa.lary@gmail.com \\ Rosmini Omar \\ Azman Hashim International Business School, Universiti Teknologi Malaysia \\ E-mail: rosmini@ibs.utm.my
}

Received: September 25, 2021 Accepted: October 16, 2021 Published: October 17, 2021

doi:10.5296/bms.v12i2.19050 URL: https://doi.org/10.5296/bms.v12i2.19050

\begin{abstract}
The small and medium-sized enterprises (SME) play a fundamental role in providing job opportunities and supporting national economy. Therefore, it is essential to increase SMEs' contributions to the economy by examining the factors that positively impact performance. As one of the main obstacles that hinder SMEs' performance is workforce-related, then organizational citizenship behavior (OCB) can contribute to performance improvement. Consequently, the current research's concern is to identify factors that are associated with employee OCB. To this end, employer branding, employee engagement and person-organization fit are proposed as antecedents of the OCB. This study contributes to the literature by identifying determinants of OCB and providing a framework that improves OCB.
\end{abstract}

Keywords: employer branding, person-organization fit, employee engagement and organizational citizenship behavior

\section{Introduction}

In an organizational setting, individuals are expected to perform certain roles as specified by 
organization. Some employees perform their role above and beyond described duties (Sharma, 2014), which is called OCB. According to Faidal (2021), OCB is "an individual contribution that exceeds the demands of a role in the workplace and is rewarded based on individual performance results". In this study, OCB manifests in behaviors that help one another, become a volunteer for extra tasks, obedient to the rules and procedures in workplace.

Employees with high level of OCB are willing to actively participate in decision making, tend to be responsible and independent while collaborating with others. OCB improves the organization's for attracting and preserving the workforce by creating desirable emotional state at employees towards company. Besides, displaying high level of OCB leads to less intention to quit and non-presence of employees at their job (Polat, 2009).

Since employee OCB strengthen the organization's ability to attract and retain the best employees and it improves overall effectiveness of the organizational operations (Podsakoff et al., 2000), there is a need to find predictors of OCB across multiple contexts. By investigating the extant literature some gaps are found to be addressed. First, there are inconsistent findings from past investigation on the impact of employer branding on employee OCB (Bhasin et al., 2019). Employer branding which means perceived attractiveness of employer brand from potential and current employee's perspective (Backhaus, 2016), needs further investigation due to its complexity and changes in the modern age (Chandler \& Nemeth, 2020). Second, little is acknowledged about the mechanism through which employer branding impacts employee OCB (Kaur \& Malhotra, 2020). In this regard, employee engagement (Chawla, 2019; Bhasin et al., 2019) and person-organization fit (Chuang et al., 2005) are suggested as variables that can be taken into the consideration while investigating the mechanism through which employer branding impacts OCB.

Concerning the theoretical underpinning, signaling theory has potential to support the proposed research framework. According to the signaling theory, one party sends information to another party and the other party to receive the information and choose how to respond. From the perspective of human resource management, signaling approach used to deliver information about working life in the organization (Dineen et al., 2019; Kaiser et al., 2019). Signals help in not only decision making for current, but also potential employees (Bergh et al., 2010). New applicants perceive positive employer behavior as signals of organizational characteristics (Chapman et al., 2005; Vinayak and Khan, 2017).

Considering the vital role OCB in improving the organizational productivity and anchoring signaling theory, this study proposes a framework encompassing employer branding, POF and employee engagement as antecedents of OCB. Accordingly, this paper aims to answer the following research questions:

RQ1 - Does employer branding influence organizational citizenship behavior?

RQ2 - Does employer branding influence perceived person organization-fit?

RQ3- Does employer branding influence Employee Engagement? 
RQ4 - Does perceived person organization-fit influence organizational citizenship behavior?

RQ5 - Does employee engagement influence organizational citizenship behavior?

The remainder of the paper is structured as follows. First, research hypotheses are discussed, followed by conceptual model. Then, research methodology to conduct this study is presented. The paper ends with conclusion and recommendations for future research.

\section{Literature Review}

Prior literature highlighted that employee OCB contributes to successful organizational performance (Sharma, 2014). According to Podsakoff et al. (2000), who is one of the prominent scholars in this field of study, OCB leads to organizational success by "enabling the organization to adapt more effectively to environmental changes". Employees who show citizenship behavior "enhance overall effectiveness and productivity of organizational operations and consequently reduces the costs". Strengthening the organization's ability to attract and retain the best employees is also stated as benefits of OCB.

Despite the fact that OCB has potential to improve individual and organizational performance, few studies have examined the predictors of organizational citizenship behavior (Khuwaja et al., 2020). Therefore, there is an increased need to explore and examine such predictors of OCB to achieve theoretical generalizability. To this end, in this paper, a comprehensive literature review is conducted to identify predictors of the OCB. The following section describes the hypothesized relationships between identified research variables including employer branding, employee engagement, person-organization fit and OCB.

\subsection{Hypotheses Development}

\subsubsection{The Relationship between Employer Branding and OCB}

Employer branding refers to the strategy that allows an organization to have a distinctive image from its competitors (Vinayak et al., 2017). When employees feel committed toward company's brand, they perform beyond the call of duty and become passionate and willing for volunteer participation in different activities that leads to organization's advocacy (Mendoza et al., 2020). In other words, a successful implementation of the employer branding practices in organization leads to exhibiting extra-role behavior and consequently greater organizational efficiency. So, it can be argued that implementing employer branding improves OCB in organization (Kaur \& Malhotra, 2020).

Özçelik and Afacan (2014) carried out a study among employees in Turkey and fund out that internal branding is significantly associated with employee OCB. Similarly, findings of a study on 316 primary respondents revealed that company's internal branding practices significantly influence employee OCB (Mendoza et al., 2020). Again, Tatar \& Ergun (2018) argue that employer branding activities affects employee OCB.

Despite the potential of OCB and its contribution to performance, relatively few studies have examined the effects of different factors on OCB (Khuwaja et al., 2020a). Particularly, there 
is lack of studies that investigate the impact of employer branding on employee OCB (Bhasin et al., 2019). Consequently, taking evidence from existing literature and concerning existing gaps, we suggest that "the more committed the employees are to the brand, the more citizenship behaviors they demonstrated through discretionary actions within the organization". Hence, the following hypothesis is suggested:

H1: "Employer branding" is positively associated with OCB

\subsubsection{The relationship between Employer Branding and Person-Organization Fit}

Person-organization fit is defined as congruence between the norms and values of organizations and the values of persons. In fact, organization's norms/values impact individual's values/behaviors and vice versa (Chatman, 1989). Employer branding is a strategic function that communicates organizational values to their stakeholders. It provides opportunity for employees to make sure that they see themselves as a best fit in the organization (Parmar, 2014). Hence, employer branding helps employee to decide whether organizational values and culture regard their values and skills (Foster et al., 2010; Tatar \& Ergun, 2018). In this sense, employer branding helps in increasing the person-organization fit. In an empirical study by Chawla (2019), the author analyzed a sample of 296 employees working in Indian organizations. The results of the structural equation modelling revealed that employer branding positively affect the person-organization fit.

As per current need of time, it is necessary to know better about the trends in what employee value and what is valued differ by business sectors (Dabirian \& Kietzmann, 2019). Further, association among person-organization fit and employee branding have not thoroughly examined. Consequently, the current study examines the influence of employer branding on person-organization fit; hence, the following hypothesis is developed:

H2: "Employer branding" is positively associated with perceived "person organization-fit"

\subsubsection{The Relationship Between Employer Branding and Employee Engagement}

Employees judged their outcomes based on what they received from the company. When the company meet employees expectations, then they would feel obliged to well respond and repay (Burawat et al., 2015). In this circumstance, employees exhibit greater levels of engagement and extra effort, which in turn enhance an organizational success.

Employer branding - employee engagement link has been empirically tested by several scholars in the past. Rana \& Sharma (2019) collected data from 245 employees in India by using convenience sampling. The findings revealed that employer branding practices such as interest value, social value, development value, and economic value positively affect employee engagement. Likewise, Swider et al. (2015) found out that there is a strong positive relationship between employer branding and employee engagement. More recently, results of regression analysis by Bhasin et al. (2019) indicate that all dimensions of employer brand (i.e. application, economic, interest, development and social value) have a significant impact on employee engagement. 
Despite some empirical evidence, research that links employer branding and employee engagement is limited (Bhasin et al., 2019). Accordingly, we argue that employees who receive well support from their employers, they put more engaged and extra effort in performing duties. In fact, employees show extra level of engagement to repay what they received from the company, which consequently contribute to organizational success. Hence, the following hypothesis is proposed:

H3: "Employer branding" is positively associated with "employee engagement"

\subsubsection{The Relationship Between Person-Organization Fit and OCB}

Empirical evidence has shown that a high level of person-organization fit is related to a number of positive outcomes, particularly employee OCB (Hoffman \& Woehr, 2006; Sekiguchi, 2004). Barrick and Parks-Leduc (2019) highlighted the importance of person-organization fit due to continuous change at the workplace. Rauvola et al. (2019) emphasized on person-environment fit that relates to individual congruence with a culture and environment which result in outcome of sustainable employment. Van Vianen, (2018) clearly stated the future research on person-organization fit with careful selection of attributes, outcomes and theory to connect both. In addition, organizational values can be considered to derive the person-organization fit subject to contextual and firm selection. Moreover, studies lack theoretical framework that examine the significance of activities perform by organizations that comes under the shed of employer branding.

Although organizational branding activities have an influence on perceived person-organization fit, this connection remains eclipse in the literature to justify employee OCB. Therefore, this study inclines to fill the gap by examining the influence of perceived Person-Organization Fit on OCB in the context of SME sector in Saudi Arabia. Accordingly, the following hypothesis is developed:

H4: Perceived "person-organization fit" is positively associated with OCB

\subsubsection{The Relationship Between Employee Engagement and OCB}

Employee engagement is one of the potential predictors of OCB. Individual who are high in employee engagement have a tendency to engage in constructive and responsible behavior at work (i.e., OCB) (Ariani, 2013). This statement is also supported by Roberts \& Davenport (2002) arguing people who are more engaged in their jobs and enthusiastic in their day-to-day work, tend to do better work. In an empirical study by Babcock-roberson (2010), the result indicated a significant positive relation between employee engagement and OCB of Indonesian employers. The authors argue that high level of employee engagement manifests in a sense of "self-investment", "energy", and "passion" which result in displaying extra-role performance (OCB). The above-mentioned findings are also confirmed in a study by Kataria (2013). His findings indicate that employee engagement has potential to drive OCB.

Recently, future research is encouraged to examine outcomes of employee engagement, such as OCB (Nhat \& Sid, 2020; Xiong \& King, 2020). Accordingly, the current study investigates 


\section{Macrothink}

the role of employee engagement from the perspective of OCB and the following hypothesis is developed:

H5: Employee engagement is positively associated with organizational citizenship behavior

Based on the research questions and research hypotheses which are discussed, a conceptual model is developed. Figure 1 presents the integrated model of employer branding and OCB. Further, a relationship between employer branding, person-organization fit and employee engagement with OCB is proposed.

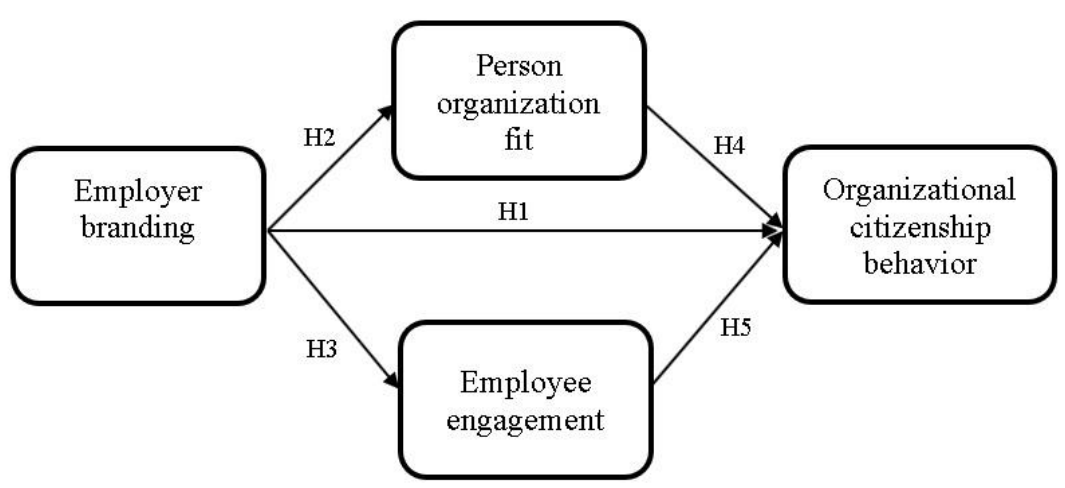

Figure 1. The proposed conceptual model in this study

\section{Research Methodology}

A questionnaire will be distributed among front-line and middle-line management employees. Scale to measure research variables is all borrowed from the past studies. In this regard, employer branding will be adapted from Berthon et al. (2005) and Dabirian and Kietzmann (2019). For measuring employee engagement, a scale will be adapted from Shrotryia and Dhanda (2019). Additionally, person-organization fit will be measured with a measurement scale developed by Tanwar and Kumar (2019). For OCB, items will be adapted from Podsakoff (1990).

To test research hypotheses, structural equation modelling (SEM), partial least square (PLS) approach will be employed, using SmartPLS version 3.3.2. SEM-PLS is recommended to be used when the researcher intend to predict a certain variable. In this study, OCB as dependent variable will be predicted by three independent variables of employer branding, employee engagement and person-organization fit.

\section{Conclusion}

The present study proposed employer branding, employee engagement and person-organization fit as antecedents of OCB. This study was limited to reviewing the literature to identify variables that may impact OCB. Hence, further studies are recommended to empirically test the proposed framework in different contexts. While testing the developed in this study, it is worthwhile to examine not only direct relationship between variables, but 
also indirect and mediating role of the person-organization fir and employee engagement on the relationship between employer branding and OCB. This paper also had limited scope for investigation and several potential factors that could impact OCB were not included. Then, it is recommendable to incorporate other factors into the model, both individual and organizational level. Entrepreneurial orientation and shared leadership are variables that can be suggested for investigation in future studies. From employee perspective, employees with high entrepreneurial orientation may show higher level of citizenship behavior in the organization. From an employer perspective, shared leadership may increase employee engagement in an organizational setting. This paper contributes to the body of knowledge by providing a new conceptual model and proposing new relationships between variables. This effort opens new avenues for future research by calling the scholars for paying more attention to undeveloped research areas.

\section{References}

Ariani, D. W. (2013). The Relationship between Employee Engagement, Organizational Citizenship Behavior, and Counterproductive Work Behavior. 4(2), 46-56. https://doi.org/10.5430/ijba.v4n2p46

Babcock-roberson, M. E. (2010). Leadership , Work Engagement , and Organizational Citizenship Behaviors. 144(3), 313-326. https://doi.org/10.1080/00223981003648336

Backhaus, K. (2016). Employer Branding Revisited Employer Branding Revisited. $\begin{array}{llll}\text { Organization Management 193-201. } & \text { Journal, }\end{array}$ https://doi.org/10.1080/15416518.2016.1245128

Barrick, M. R., \& Parks-Leduc, L. (2019). Selection for Fit. Annual Review of Organizational Psychology and Organizational Behavior, 6, 171-193. https://doi.org/10.1146/annurev-orgpsych-012218-015028

Bergh, D. D., Ketchen, D. J., Boyd, B. K., \& Bergh, J. (2010). New Frontiers of the Reputation - Performance Relationship : Insights From Multiple Theories. 36(3), 620-632. https://doi.org/10.1177/0149206309355320

Berthon, P., Ewing, M., \& Hah, L. L. (2005). Captivating company: Dimensions of attractiveness in employer branding. International Journal of Advertising, 24(2), 151-172. https://doi.org/10.1080/02650487.2005.11072912

Bhasin, J., Mushtaq, S., \& Gupta, S. (2019). Engaging Employees Through Employer Brand: An Empirical Evidence. Management and Labour Studies, 44(4), 417-432. https://doi.org/10.1177/0258042x19870322

Biswas, M. K., \& Suar, D. (2014). Antecedents and Consequences of Employer Branding. June. https://doi.org/10.1007/s10551-014-2502-3

Burawat, P., Chanongkorn, K., \& Panisa, M. (2015). The Relationships among Perceived Employer Branding, Employee Engagement, and Discretionary Effort. Sranaree Journal of 
Social Sciences, 9(1), 37-60.

Celani, A. (2010). Signaling theory and applicant attraction outcomes. https://doi.org/10.1108/00483481111106093

Chandler, N. G., \& Nemeth, T. (2020). Employer Branding: Issues of Tailoring Your Message in the Modern Age. 37-50. https://doi.org/10.1007/978-3-030-19289-1_3

Chapman, D. S., Uggerslev, K. L., Carroll, S. A., Piasentin, K. A., \& Jones, D. A. (2005). Applicant attraction to organizations and job choice: A meta-analytic review of the correlates of recruiting outcomes. Journal of Applied Psychology, 90(5), 928-944. https://doi.org/10.1037/0021-9010.90.5.928

Chatman, J. A. (1989). Improving Interactional Organizational Research: A Model of Person-Organization Fit. The Academy of Management Review, 14(3), 333. https://doi.org/10.2307/258171

Chawla, P. (2019). Impact of employer branding on employee engagement in business process outsourcing (BPO) sector in India: mediating effect of person-organization fit. Industrial and Commercial Training, 15(1), 35-49. https://doi.org/10.1108/ICT-06-2019-0063

Chuang, A., Sackett, R., Campbell, J. P., Ones, D. S., \& Road, R. (2005). The Perceived Importance of Person-Job Fit And Person-Organization Fit Between and Within Interview Stages, 33(85), 209-226. https://doi.org/10.2224/sbp.2005.33.3.209

Dabirian, A., \& Kietzmann, J. (2019). Enticing the IT crowd: employer branding in the information economy. Journal of Business \& Industrial Marketing, August 2019. https://doi.org/10.1108/JBIM-11-2018-0333

Dineen, B. R., Lievens, F., Dineen, B. R., Hoye, G. Van, Lievens, F., \& Rosokha, L. M. (2019). Institutional Knowledge at Singapore Management University Third party employment branding: What are its signaling dimensions, mechanisms, and sources? Chapter 5 Third party Employment Branding: What are its Signaling Dimensions. Mechanisms , and So. https://doi.org/10.1108/S0742-730120190000037006

Foster, C., Punjaisri, K., \& Cheng, R. (2010). Exploring the relationship between corporate, internal and employer branding. Journal of Product and Brand Management, 19(6), 401-409. https://doi.org/10.1108/10610421011085712

Hoffman, B. J., \& Woehr, D. J. (2006). A quantitative review of the relationship between person-organization fit and behavioral outcomes. Journal of Vocational Behavior, 68(3), 389-399. https://doi.org/10.1016/j.jvb.2005.08.003

Kaiser, M., Regjepaj, A., Kaiser, M., \& Regjepaj, A. (2019). Impact of Employer Branding on Employee Commitment and Satisfaction Moderated by Generation X and Y. International Business and Marketing.

Kataria, A. (2013). Employee Engagement and Organizational Effectiveness : The Role of Organizational Citizenship Behavior. 6(1). 
Kaur, P., \& Malhotra, K. (2020). Employer Branding and Organisational Citizenship Behaviour: The Mediating Role of Job Satisfaction. https://doi.org/10.1177/2319510X20931716

Khuwaja, U., Khuwaja, U., Abid, G., \& Adeel, A. (2020a). Ac ce pt us cr ip t Leadership and employee attitudes: The mediating role of Accept uscrt. https://doi.org/10.1080/23311975.2020.1720066

Khuwaja, U., Khuwaja, U., Abid, G., \& Adeel, A. (2020b). Leadership and employee attitudes: The mediating role of perception of organizational politics. https://doi.org/10.1080/23311975.2020.1720066

Mendoza, M. C. A., Orosa, L. A. B., \& Recto, J. G. S. (2020). Internal Branding Practices and Organizational Citizenship Behavior as Antecedents of Corporate Sustainability Performance : An Empirical Test using a Large Food Processing Company ... November 2019, 0-22.

Nhat, B., \& Sid, S. (2020). The impact of human resource management practices on employee engagement and moderating role of gender and marital status : An evidence from the Vietnamese banking industry. 10, 1633-1648. https://doi.org/10.5267/j.msl.2019.12.003

Özçelik, G., \& Afacan, M. (2014). The Relationship between Internal Branding and Organizational Citizenship Behaviour: The Mediating Role of Person-Organization Fit. Procedia-Social and Behavioral Sciences, 150, 1120-1128. https://doi.org/10.1016/j.sbspro.2014.09.127

Parmar, A. A. (2014). The Role of Hr Department in Employer Branding at Public and Private Sector, 2(2), 201-225.

Podsakoff, P. M. (1990). Transformational Leader Behaviors and Their Effects on Followers' Trust in Leader, Satisfaction, and Organizational. American Journal of Obstetrics and Gynecology, 193(5), 1599-1604. https://doi.org/10.1016/j.ajog.2005.07.085

Podsakoff, P. M., Mackenzie, S. B., Paine, J. B., \& Bachrach, D. G. (2000). Organizational Citizenship Behaviors: A Critical Review of the Theoretical and Future Research. 26(3), 513-563.

Polat, S. (2009). Organizational citizenship behavior (OCB) display levels of the teachers at secondary schools according to the perceptions of the school administrators. Procedia Social and Behavioral Sciences, 1(1), 1591-1596. https://doi.org/10.1016/j.sbspro.2009.01.280

Rana, G., \& Sharma, R. (2019). Assessing Impact of Employer Branding on Job Engagement: A Study of Banking Sector. Emerging Economy Studies, 5(1), 7-21. https://doi.org/10.1177/2394901519825543

Rauvola, R. S., Rudolph, C. W., Ebbert, L. K., \& Zacher, H. (2019). Person-Environment Fit and Work Satisfaction: Exploring the Conditional Effects of Age. Work, Aging and Retirement, $X X(\mathrm{Xx}), 1-17$. https://doi.org/10.1093/workar/waz011 
Roberts, D. R., \& Davenport, T. O. (2002). Job Engagement : Why It's Important and How to Improve It. 21-29. https://doi.org/10.1002/ert.10048

Sekiguchi, T. (2004). Person-Organization fit and Person-Job fit in employee selection: A review of the literature. Osaka Keidai Ronshu, 54(6), 179-196.

Sharma, V. (2014). A Scale for Measuring Organizational Citizenship Behavior in Manufacturing Sector. 6(8), 57-62.

Shrotryia, V. K., \& Dhanda, U. (2019). Content Validity of Assessment Instrument for Employee Engagement. SAGE Open, 9(1). https://doi.org/10.1177/2158244018821751

Swider, B. W., Zimmerman, R. D., \& Barrick, M. R. (2015). Searching for the right fit: Development of applicant person-organization fit perceptions during the recruitment process. Journal of Applied Psychology, 100(3), 880-893. https://doi.org/10.1037/a0038357

Tanwar, K., \& Kumar, A. (2019). Employer brand , person-organisation fit and employer of choice Investigating the moderating effect. https://doi.org/10.1108/PR-10-2017-0299

Tatar, B., \& Ergun, S. (2018). Employer branding and employee attitudes: Mediating role of person- organization fit Employer Branding And Employee Attitudes. Mediating Role of Person-Organization. June. https://doi.org/10.17261/Pressacademia.2018.830

Van Vianen, A. E. M. (2018). Person-environment fit: A review of its basic tenets. Annual Review of Organizational Psychology and Organizational Behavior, 5(January), 75-101. https://doi.org/10.1146/annurev-orgpsych-032117-104702

Vinayak, P. C., \& Khan, B. M. (2017). Role of Signalling Theory in Potential Applicant Attraction: An Employer Branding Perspective. April. https://doi.org/10.23956/ijermt/V7I3/0188

Vinayak, P. C., Khan, B. M., \& Jain, M. C. (2017). Role of Signalling Theory in Potential Applicant Attraction: An Employer Branding Perspective. International Journal of Emerging Research in Management and Technology, 6(4), 230-233. https://doi.org/10.23956/ijermt/v7i3/0188

Xiong, L., \& King, C. (2020). Exploring How Employee Sense of Brand Community Affects Their Attitudes and Behavior. Journal of Hospitality and Tourism Research, 44(4), 567-596. https://doi.org/10.1177/1096348020905360

\section{Copyright}

Copyright for this article is retained by the author(s), with first publication rights granted to the journal.

This is an open-access article distributed under the terms and conditions of the Creative Commons Attribution license (http://creativecommons.org/licenses/by/4.0/). 